\title{
Soft Palate Dimensions and Nasopharyngeal Depth (Need's Ratio) In Different Sagittal and Vertical Skeletal Patterns: A Lateral Cephalometric Study
}

\author{
Aisha Khoja* \\ Department of Orthodontics, Aga Khan University Hospital, Pakistan
}

Submission: February 18, 2017; Published: February 27, 2018

*Corresponding author: Aisha Khoja, Department of Orthodontics, Aga Khan University Hospital, Karachi, Pakistan, Email: dr.aisha86@gmail.com

\begin{abstract}
Objectives: Are to compare the soft palate length (SPL), width and nasopharyngeal depth (PD) in different sagittal and vertical skeletal patterns and to see the influence of different skeletal malocclusions on need's ratio (PD/SPL).

Material \& Methods: Lateral cephalograms of 372 patients were equally divided into sagittal (class I, II, III) and vertical skeletal patterns (normodivergent, hypodivergent, hyperdivergent) by measuring ANB and SN-MP angles, respectively. SPL, velar width (VW) and PD were recorded using Rogan Delft View Pro-X software. Kruskal Wallis test was used to compare SPL, VW, PD and need's ratio between sagittal and vertical skeletal groups. Intergroup comparisons were performed using Mann-Whitney U-test. Level of significance was kept at $p \leq 0.05$.

Results: Statistically significant differences were found for VW $(\mathrm{p}=0.008)$ and need's ratio $(\mathrm{p}=0.035)$ amongst sagittal groups. Amongst vertical groups, significant differences were found for SPL $(p<0.001)$, VW $(p=0.021)$ and needs ratio $(p=0.020)$. On intergroup comparison, SPL ( $\mathrm{p}=0.031)$, VW ( $\mathrm{p}=0.011)$ and Need's ratio $(\mathrm{p}=0.013)$ were significantly different between skeletal class I and III and VW ( $p=0.005)$ between skeletal class II and III malocclusions. The SPL was significantly different between normodivergent and hypodivergent $(\mathrm{p}=0.004)$ and normodivergent and hyperdivergent groups $(\mathrm{p}<0.001)$. The VW was significantly different between hyperdivergent and hypodivergent groups $(p=0.005)$ and needs ratio between normodivergent and hyperdivergent groups $(p=0.001)$. Gender difference was significant for SPL which was larger in males as compared to females in skeletal class III malocclusion $(\mathrm{p}=0.001)$.
\end{abstract}

Conclusion: Soft palate length, width and need's ratio may vary with the underlying skeletal malocclusion.

Keywords: Need's ratio; Soft palate; Lateral cephalogram

\section{Introduction}

The roof of the mouth anatomically separates the nasal cavity from the oral cavity and structurally is composed of anterior bony component i.e. hard palate and posterior fibro-muscular component i.e. soft palate (also known as velum) [1,2]. The contribution of the soft palate towards velopharyngeal closure is related to normal oral functions of sucking, deglutition, and articulation [3]. The velopharynx is a roughly rectangular space which is bordered anteriorly by velum (soft palate), posteriorly by posterior pharyngeal wall, and laterally by right and left lateral pharyngeal walls [4]. The contractions of these structures assist in closure of velopharyngeal port during the acts of eating, swallowing and speaking whereas; their relaxation opens the port for breathing and in producing specific nasalized articulations. A close coordination of the soft palate with the posterior pharyngeal wall is important during pronouncing most of the vowels and consonants [3] The failure of velopharyngeal sphincter mechanism to perform these aforementioned functions results in velopharyngeal dysfunction [4-6].
The relationship between soft palate length (SPL) and nasopharyngeal depth (PD) can be used to determine the velopharyngeal function and is called the Need's ratio (PD/ SPL). According to Subtelny [7], the Need's ratio should be in a range of 0.6-0.7 in normal subjects. Likewise, Simpson \& Colton [8] and Hoopes et al. [9] found the normal ratio to be 0.75 to 0.8 . Any increase greater than $80 \%$ demonstrated a risk for developing velopharyngeal insufficiency [10]. This ratio is of paramount interest in detecting speech related problems and can be influenced by dentofacial orthopedics, adenoidectomy, uvulopalatopharyngoplasty and maxillary advancement surgeries [11].

Soft palate dysfunctions are most commonly observed in cleft palate patients who have short or otherwise abnormal velum, sub mucous cleft palate, excessively large tonsils or adenoids, webbing of the posterior tonsillar pillars, obstructive sleep apnea or skeletal craniofacial malocclusions $[2,12]$. There have 


\section{Advances in Dentistry \& Oral Health}

been studies in the literature that have evaluated the soft palate and airway dimensions in different sagittal and vertical skeletal malocclusions [13-15], but little work has been done to see the relationship of soft palate length with the nasopharyngeal depth (need's ratio) in these malocclusions [15].

Hence, the objective of this study was to compare the soft palate length, width and nasopharyngeal depth in different sagittal (skeletal class I, II and III malocclusions) and vertical (normodivergent, hypodivergent and hypedivergent) skeletal patterns and to see if the need's ratio is affected by changes in the underlying skeletal patterns.

Since a number of adult patients who seek orthodontic treatment may require orthognathic surgeries as well as multiple cleft patients with hypernasal speech may undergo Le-Fort I maxillary advancement, the pre-surgical assessment of the need's ratio is important. This will help us in planning appropriate jaw movements during orthognathic surgeries in treatment of underlying sagittal skeletal discrepancies. In addition, patients presented with moderate to severe skeletal class II malocclusion with pre-existing enlarged adenoids or tonsils, allergies, asthma or obesity may develop obstructive sleep apnea (OSA) in future [16]. Knowledge about the difference in soft palate length and width, nasopharyngeal dimensions and Need's ratio in different skeletal malocclusions will assist in better understanding of the etiology of OSA syndrome.

\section{Materials and Methods}

Sample size was calculated by using NCSS statistical software (version 13), keeping $\alpha=0.05$, power of study $(\beta)$ as $80 \%$ and by using the findings of a study conducted by Abu Allhaija \& AlKhateeb [13]. They reported the mean and SD of soft palate length (PNS-P) amongst the three skeletal malocclusions as (class I= 36.7 \pm 3.7 , class $\mathrm{II}=37.2 \pm 4.6$, class $\mathrm{III}=34.7 \pm 4.7$ ). A power analysis showed that we required a minimum sample of 62 subjects for one group. Since, there were three sagittal groups (skeletal class I, II and III) and three vertical groups (normodivergent, hypo divergent and hyper divergent) in this study; a total sample calculated was 372 subjects.

Ethical clearance was obtained from the institutional Ethical review Committee, prior to the data collection. The inclusion criteria of this study were pre-treatment lateral cephalograms of adult patients seeking orthodontic treatment, aged 16-35 years. A total of 372 Lateral cephalograms of the patients were equally divided into sagittal (class I, II and III) and vertical skeletal patterns (normodivergent, hypodivergent and hyper divergent) on the basis of ANB and SN-MP angles, respectively. For the sagittal groups, this was assessed on pre-treatment lateral cephalometric tracings by measuring ANB angle (Figure 1). The ANB angle was set at $1-4^{\circ},>5^{\circ}$ and $<0^{\circ}$ for skeletal class I, II and III malocclusions, respectively. The vertical malocclusion groups were categorized by measuring SN-MP angle into normodivergent (SN-MP = 33$\left.37^{\circ}\right)$, hypo divergent $\left(\mathrm{SN}-\mathrm{MP}<32^{\circ}\right)$, and hyper divergent facial patterns $\left(\mathrm{SN}-\mathrm{MP}>38^{\circ}\right)$ as shown in Figure 2.

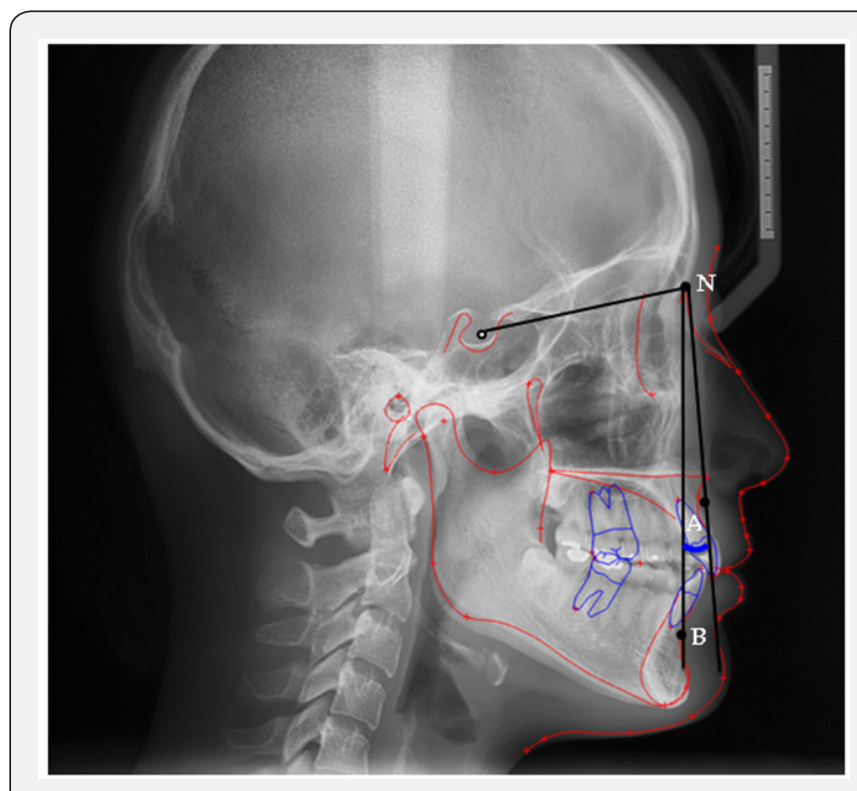

Figure 1: Measurement of ANB angle to Categorize Skeletal Malocclusions.

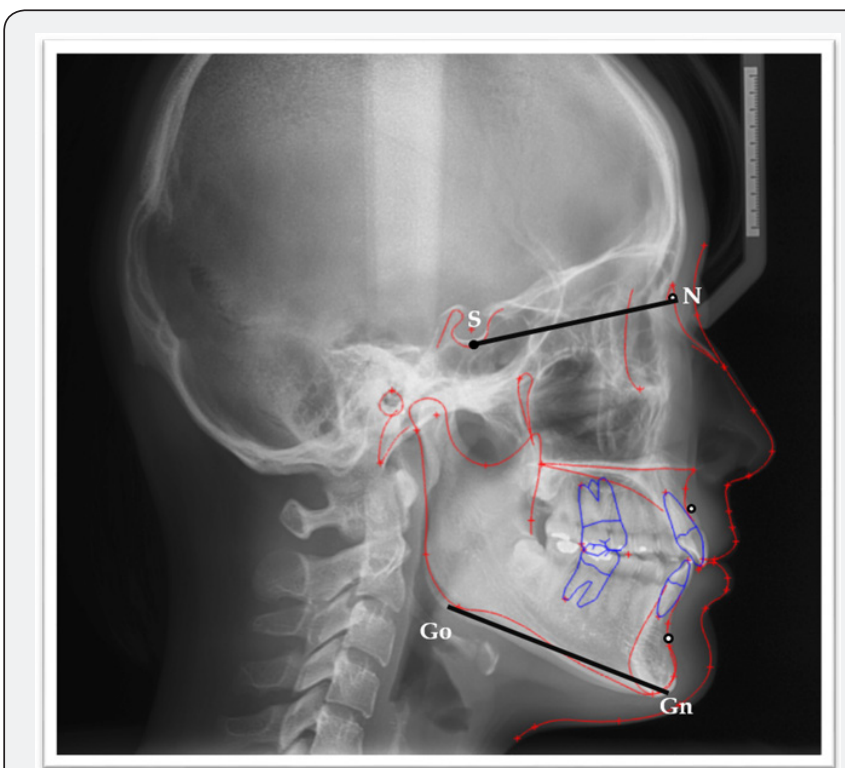

Figure 2: Measurement of SN-MP angle to Categorize Skeletal Malocclusions.

The exclusion criteria of this study were radiographs of patients with cleft palate, any systemic disease that may affect head and neck region, craniofacial syndromes, fractures of head and neck, pharyngeal pathology, nasal obstruction, enlarged tonsils or adenoids and any previous history of orthodontic treatment.

To keep a high degree of precision, all the pre-treatment lateral cephalograms of subjects were routinely taken with the sagittal plane at right angle to the path of x-ray beams, the head in an erect position, Frankfort horizontal plane being parallel to the horizontal, teeth in centric occlusion and lips closed in a relaxed position. These radiographs were recorded with rigid head fixation and a 165 -cm film-to-tube distance using Orthoralix R 9200 (Gendex-KaVo, Milan, Italy). 


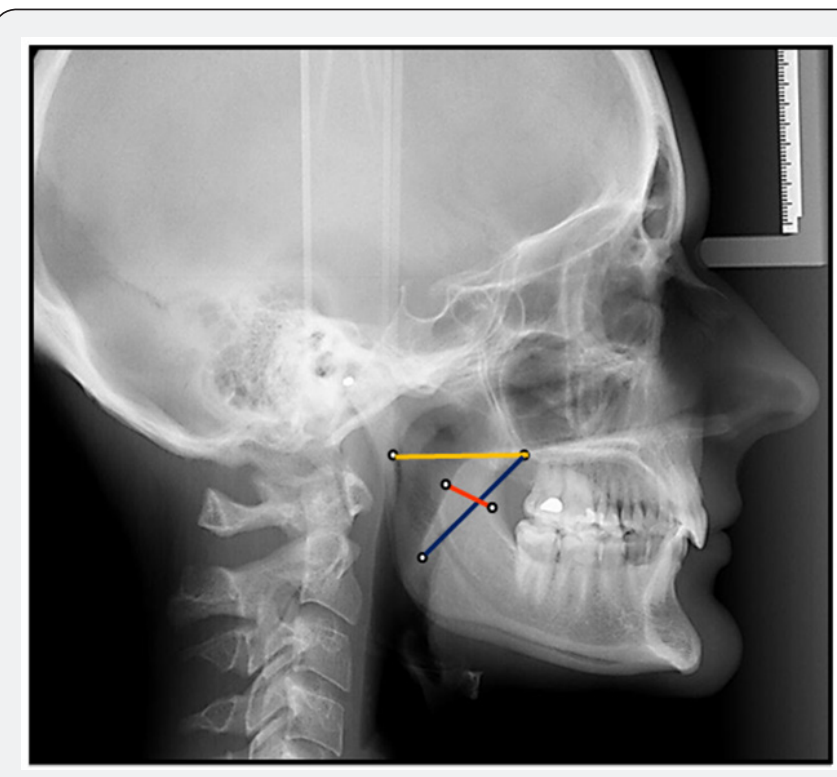

Figure 3: Measurement of Velar Length, Velar Width and Pharyngeal Depth (PD).

Lateral cephalograms were viewed and analyzed digitally on Rogan Delft View Pro-X software. The soft palate length (SPL) was measured as a linear distance from the posterior nasal spine (PNS) to the tip of the uvula of the resting soft palate. The velar width (VW) was measured at the thickest section of the velum. The nasopharyngeal depth (PD) was taken as a linear measurement from the posterior nasal spine to the posterior pharyngeal wall along the palatal plane (Figure 3). The Need's ratio was calculated for all the subjects by dividing the pharyngeal depth (PD) with soft palate length (SPL). To avoid the examiner bias, 20 lateral Table 1: Comparison of Soft Palate and Pharyngeal Dimensions among cephalograms were randomly selected after a month and reevaluated to assess the intra-examiner reliability.

\section{Statistical Analysis}

All the statistical analyses of data were performed using the SPSS for Windows (version 19.0, SPSS Inc. Chicago). Shapiro-Wilk test was used to explore the normality of the data which showed a non-normal distribution for most of the variables. Descriptive statistics such as mean and SD were calculated for the soft palate length, width, nasopharyngeal depth and Needs ratio (PD/SPL) and Kruskal Wallis test was used to compare these variables between sagittal and vertical skeletal patterns. Intergroup comparisons between different sagittal and vertical skeletal patterns were performed using Mann-Whitney U-test. For intersex comparison, similar statistical tests were performed. Level of significance was kept at $\mathrm{p} \leq 0.05$

\section{Results}

A total sample comprised of 372 subjects who were further divided equally into sagittal groups [class $\mathrm{I}=62$, class $\mathrm{II}=62$ and class III $=62$ ] and vertical groups (normodivergent $=62$, hypodivergent $=62$, hyperdivergent $=62]$. Each sagittal and vertical malocclusion group was further subdivided into 31 males and 31 females. Descriptive statistics such as mean and SD was calculated for chronological age of the subjects. The mean age of subjects in skeletal class I, II and II malocclusions were $22.4 \pm$ $6.04,21.2 \pm 5.67$ and $19.3 \pm 4.13$ years, respectively. In vertical malocclusion groups, the mean age of subjects were $18.8 \pm 3.07$, $22.5 \pm 6.03$ and $22.7 \pm 6.93$ for normodivergent, hypodivergent and hyperdivergent skeletal patterns, respectively.

\begin{tabular}{|c|c|c|c|c|}
\hline Variable & $\begin{array}{c}\text { Skeletal Class I } \\
(\mathbf{n}=\mathbf{6 2}) \\
\text { Mean } \pm \text { SD }\end{array}$ & $\begin{array}{c}\text { Skeletal Class II } \\
(\mathbf{n}=\mathbf{6 2}) \\
\text { Mean } \pm \text { SD }\end{array}$ & $\begin{array}{c}\text { Skeletal Class II } \\
(\mathbf{n}=\mathbf{6 2}) \\
\text { Mean } \pm \text { SD }\end{array}$ & $\mathbf{p}$ \\
\hline Velar Length & $36.3 \pm 3.61$ & $35.6 \pm 4.01$ & $34.6 \pm 3.32$ & 0.085 \\
\hline Velar Width & $9.18 \pm 2.21$ & $9.12 \pm 1.95$ & $10.23 \pm 1.86$ & $0.008^{*}$ \\
\hline Pharyngeal Depth & $27.0 \pm 4.13$ & $27.1 \pm 3.42$ & $26.4 \pm 3.67$ & 0.737 \\
\hline Need's Ratio & $0.73 \pm 0.11$ & $0.75 \pm 0.12$ & $0.76 \pm 0.11$ & $0.035^{*}$ \\
\hline
\end{tabular}

$N=186$; Kruskal Wallis test; $p<0.05^{*}$

Table 2: Comparison of Soft Palate and Pharyngeal Dimensions amongst Different Vertical Patterns of Malocclusions.

\begin{tabular}{|c|c|c|c|c|}
\hline Variables & $\begin{array}{c}\text { Normodivergent } \\
(\mathbf{n}=\mathbf{6 2}) \\
\text { Mean } \pm \mathbf{S D}\end{array}$ & $\begin{array}{c}\text { Hypodivergent } \\
(\mathbf{n}=\mathbf{6 2}) \\
\text { Mean } \pm \mathbf{S D}\end{array}$ & $\begin{array}{c}\text { Hyperdivergent } \\
(\mathbf{n}=\mathbf{6 2}) \\
\text { Mean } \pm \text { SD }\end{array}$ & $\begin{array}{c}\text { Hyperdivergent } \\
(\mathbf{n}=\mathbf{6 2}) \\
\text { Mean } \pm \mathbf{S D}\end{array}$ \\
\hline Velar Length & $35.0 \pm 3.14$ & $36.2 \pm 4.77$ & $37.6 \pm 2.61$ & $<0.001^{* *}$ \\
\hline Velar Width & $9.55 \pm 2.13$ & $9.29 \pm 2.27$ & $10.09 \pm 1.16$ & $0.021^{*}$ \\
\hline Pharyngeal Depth & $26.6 \pm .30$ & $28.3 \pm 4.31$ & $27.6 \pm 2.47$ & 0.27 \\
\hline Need's Ratio & $0.76 \pm 0.11$ & $0.76 \pm 0.14$ & $0.73 \pm 0.05$ & $0.020^{*}$ \\
\hline
\end{tabular}

$N=186$; Kruskal Wallis test; $p<0.05^{*}$ 
The comparison of velar length, velar width, pharyngeal depth and Need's ratio between different sagittal and vertical skeletal patterns are shown in (Table $1 \& 2$ ). The results indicated statistically significant differences for velar width $(p=0.008)$ and Need's ratio $(p=0.035)$ amongst the three sagittal malocclusions. However, the velar length and pharyngeal depth didn't change significantly.

Amongst the vertical groups, statistically significant difference were found for velar length $(\mathrm{p}<0.001)$, velar width $(\mathrm{p}=0.021)$ and needs ratio $(\mathrm{p}=0.020)$. The pharyngeal depth didn't change significantly amongst the vertical groups $(p=0.270)$.
Inter-group comparisons were further made using Mann Whitney U-test. The velar length $(\mathrm{p}=0.031)$, velar width $(\mathrm{p}=$ $0.011)$ and Need's ratio $(p=0.013)$ were significantly different between skeletal class I and III malocclusions. The velar width $(\mathrm{p}=0.005)$ was found to be significantly different between skeletal class II and III malocclusions. Amongst the vertical malocclusion groups, velar length was significantly different between normodivergent and hypodivergent $(p=0.004)$ groups and normodivergent and hyperdivergent groups $(\mathrm{p}<0.001)$. The velar width was significantly different between hyperdivergent and hypodivergent groups ( $p=0.005)$ whereas, the change in needs ratio was statistically significant between normodivergent and hyperdivergent groups ( $\mathrm{p}=0.001$ ) (Table 3).

Table 3: Intergroup Comparison of Variables between Different Sagittal and Vertical Patters of Malocclusions.

\begin{tabular}{|c|c|c|c|c|}
\hline $\begin{array}{c}\text { Intergroup } \\
\text { Comparison }\end{array}$ & Velar Length & Velar Width & Pharyngeal Depth & Needs Ratio \\
\hline Skeletal class I vs. II & $\mathbf{p}$ & $\mathbf{p}$ & 0.637 & 0.159 \\
\hline Skeletal class I vs. III & 0.581 & 0.84 & 0.673 & $0.013^{*}$ \\
\hline Skeletal class II vs. III & $0.031^{*}$ & $0.011^{*}$ & 0.47 & 0.17 \\
\hline $\begin{array}{c}\text { Normodivergent vs. } \\
\text { hypodivergent }\end{array}$ & $0.004^{*}$ & $0.005^{*}$ & 0.098 & $0.001^{*}$ \\
\hline $\begin{array}{c}\text { Normodivergent vs } \\
\text { hyperdivergent }\end{array}$ & $<0.001^{* *}$ & 0.527 & 0.279 & 0.232 \\
\hline $\begin{array}{c}\text { Hypodivergent vs } \\
\text { hyperdivergent }\end{array}$ & 0.343 & 0.064 & 0.808 & \\
\hline
\end{tabular}

$N=186$; Mann-Whitney U-test; $p \leq 0.05^{*} ; p<0.001^{* *}$

Table 4: Comparison of Soft Palate and Pharyngeal Dimension among Males and Females.

\begin{tabular}{|c|c|c|c|c|c|c|c|c|c|}
\hline \multirow[t]{2}{*}{ Variables } & \multicolumn{3}{|c|}{$\begin{array}{l}\text { Skeletal Class I } \\
\text { Mean } \pm \text { SD }\end{array}$} & \multicolumn{3}{|c|}{$\begin{array}{l}\text { Skeletal Class I } \\
\text { Mean } \pm \text { SD }\end{array}$} & \multicolumn{3}{|c|}{$\begin{array}{c}\text { Skeletal Class III } \\
\text { Mean } \pm \text { SD }\end{array}$} \\
\hline & Males & Females & $\mathbf{p}$ & Males & Females & $\mathbf{p}$ & Males & Females & $\mathbf{p}$ \\
\hline Velar Length & $36.4 \pm 6.92$ & $36.2 \pm 3.32$ & 0.955 & $35.7 \pm 4.43$ & $35.5 \pm 3.61$ & 0.888 & $36.0 \pm 3.54$ & $33.3 \pm 2.43$ & $0.001^{*}$ \\
\hline Velar Width & $9.37 \pm 2.65$ & $8.99 \pm 1.68$ & 0.245 & $9.42 \pm 2.15$ & $8.82 \pm 1.71$ & 0.111 & $10.8 \pm 1.65$ & $9.65 \pm 1.89$ & 0.021 \\
\hline $\begin{array}{c}\text { Pharyngeal } \\
\text { Depth }\end{array}$ & $26.2 \pm 4.92$ & $27.7 \pm 3.03$ & 0.018 & $26.9 \pm 2.87$ & $27.3 \pm 3.93$ & 0.535 & $26.5 \pm 3.92$ & $26.2 \pm 3.46$ & 0.144 \\
\hline Need's Ratio & $0.70 \pm 0.10$ & $0.74 \pm 0.11$ & 0.230 & $0.74 \pm 0.10$ & $0.75 \pm 0.12$ & 0.587 & $0.74 \pm 0.13$ & $0.77 \pm 0.08$ & 0.204 \\
\hline
\end{tabular}

$\mathrm{N}=186$; Mann Whitney U-test; $\mathrm{p} \leq 0.017^{*}$ (Bonferroni correction)

Table 4 presents the intersex comparison of the variables. The velar length was significantly larger in males as compared to females in skeletal class III malocclusion ( $p=0.001)$. The other quantitative variables did not show significant gender differences.

To determine the intra-examiner reliability for the repeated measurements, Intra class Correlation Coefficients (ICC) was applied. The coefficients obtained were above 0.9 for all the variables, confirming the reliability of the repeated measurements.

\section{Discussion}

Lateral cephalometric radiographs have been used since many years for evaluating soft palate and nasopharyngeal dimensions in patients with obstructive sleep apnea and cleft palate as well as in normal individuals. In addition, several studies have assessed the of the soft palate and superior pharyngeal space with more sophisticated and advanced radiographic techniques such as cine-computed tomography (CT), nasopharyngoscopy, videofluoroscopy and magnetic resonance imaging (MRI) $[15,17,18]$. However, due to their increased cost and high radiation dose, they are better reserved for patients with some known soft palate dysfunctions or velopharnygeal incompetency.

Lateral cephalometric radiograph is relatively less expensive and are more useful in patients seeking orthodontic treatment, have reduced radiation exposure and provides good visibility of the soft palate and its surrounding structures [19]. In addition, it also reveals a variety of craniofacial characteristics which are often associated with patients of obstructive sleep apnea [18]. Jhonston \& Richardson [20] found that small and retrognathic 
skeletal structures, reduced airway and increased length and width of soft palate poses a risk for developing OSA. In our study, Type 5 (S-shaped) soft palate was longest and found in $9.1 \%$ of the total patients, the vast majority of which had skeletal class II malocclusion. The increased frequency of S-shaped soft palate (which was found to be the longest soft palate type) in skeletal class II malocclusion patients who have retrognathic jaws may further add the risk of developing OSA. The S-shaped soft palate was observed in $4.7 \%$ of the subjects in a study conducted by Verma et al. [21], $3.5 \%$ in You et al. [12] research and in $1.5 \%$ of the cases in Guttal et al. [22] study.

The present study used Rogan Delft View Pro X software for morphological assessment of soft palate as well as its dimensions on lateral cephalogram in different skeletal malocclusions. This software enabled us to use the magnification tool for better visualization of the soft palate type as well as allowed us to adjust and optimize the contrast and gradation. The soft palate and nasopharyngeal dimensions in different skeletal malocclusions have been investigated in several previous studies [13-15]. Abu Allhaija and Al-Khateeb [13] did not find any significant differences for the soft palate length, soft palate thickness and nasophryngeal dimensions amongst skeletal Class I, II and III malocclusions. Likewise, a study conducted by Soheilifar et al [14] reported insignificant differences for soft palate dimensions and pharyngeal depth between skeletal class I and II subjects. In our study, we found statistically significant differences for the soft palate length and thickness between skeletal class I and III and soft palate width between skeletal class II and III malocclusions. The soft palate was largest in skeletal class I and widest in skeletal class III malocclusion. However, the differences in nasopharyngeal depth were insignificant.

The growth of the soft palate in length with an increasing age has been investigated by Suntelny [7]. He found a rapid increase in growth during the early years of life which levels off till the age of 5 years. However, the growth of nasopharyngeal dimensions remain continue till 13 years and then plateau till adulthood $[13,23]$. To rule out the influence of growth on these structures, we have included adult subjects in this study. This ensures that the soft palate length and pharyngeal depth of all the subjects had almost reached their maximum size.

For intersex comparisons, Subtelny [7] in his study found an increased length of soft palate in males as compared to females. In contrast, Abu Allhaija and Al-Khateeb [13] didn't find any significant gender differences in soft palate and nasopharyngeal dimensions in different skeletal malocclusions. In our study, males had increased velar length in skeletal class III malocclusion group as compared to the females. In skeletal class I and class II, no significant differences were observed for any of the study variables across the gender.

An increase in this ratio above the normal range may disturb the normal velopharyngeal function which may result in problem related to speech and resonance. Short soft palates along with an increased nasopharyngeal depth are important etiological factors in developing velopharyngeal insufficiency especially in patients undergoing maxillary advancement surgeries [15]. Haapanen et al [24], found $27 \%$ of the patients with cleft palate demonstrated reduced velopharyngeal function following Le-fot I maxillary advancement procedure. Our study results showed statistically significant differences for the Need's ratio between skeletal class I and III malocclusions.

\section{Clinical Implications}

The variation in Need's ratio amongst different skeletal malocclusions calls attention towards thorough radiographic examination of soft palate dimensions and nasopharyngeal depth during orthodontic diagnosis and treatment planning. Any treatment plan that may affect the stability of the Need's ratio should be avoided in order to prevent speech related problems and obstructive sleep apnea. For instance, cleft palate patients with known velopharyngeal insufficiency having severe skeletal class III malocclusion due to maxillary deficiency, a double jaw surgery approach is preferred over single jaw osteotomy. A combination of Le-Fort I maxillary advancement and bilateral sagittal split osteotomy to set back the mandible will camouflage the severity of the discrepancy without compromising the velopharyngeal function. In addition, patients who had pharyngoplasty or pharyngeal flap procedures in the past pose a certain limitation towards maxillary advancement and may require revision of soft tissue surgeries in order to prevent hypernasality. The other option is to use autologous costochondral bone graft in the maxillary gap following Lefort I advancement procedure. This results in better prognosis and stable treatment results [10].

\section{Conclusion}

a) soft palate length, width and Need's ratio may vary with the underlying skeletal malocclusions

b) Males had increased soft palate length in skeletal class III malocclusion.

\section{References}

1. Wingerd, Bruce D (1994) The Human Body Concepts of Anatomy and Physiology. Fort Worth: Saunders College Publishing USA pp. 166.

2. Moore KL, Agur AMR (2002) Essential clinical anatomy (2nd edn), Lippincott, Williams and Wilkins, Baltimore, Philadelphia, PA, USA.

3. Johns DF, Rohrich RJ, Awada M (2003) Velopharyngeal incompetence: a guide for clinical evaluation. Plas Reconstr Surg 112(7): 1890-1897.

4. Yellinedi R, Damalacheruvu MR (2013) Is there an optimal resting velopharyngeal gap in operated cleft palate patients? Indian J Plast Surg 46(1): 87-91.

5. Marsh JL (2004) The evaluation and management of velopharyngeal dysfunction. Clin Plast Surg 31(2): 261-269.

6. Marsh JL (2003) Management of velopharyngeal dysfunction: Differential diagnosis for differential management. J Craniofac Surg 14(5): 621-628.

7. Subtelny JDC (1957) ephalometric study of the growth of the soft palate. Plast Reconst Surg 19(1): 49-62. 
8. Simpson RK, Colton J (1980) A cephalometric study of velar stretch in adolescent subjects. Cleft palate J 17: 40-47.

9. Hoopes JE, Dellon AL, Fabrikant JI, Edgerton MT Jr, Solimon AH (1970) Cineradiographic definition of the velopharynx. Cleft Palate J 7: 443454.

10. Nahai FR, Williams JK, Burstein FD, Martin J, Thomas J (2005) The Management of Cleft Lip and Palate: Pathways for Treatment and Longitudinal Assessment. Semin Plast Surg 19(4): 275-285.

11. Stellzig-Eisenhauer A (2001) The influence of cephalometric parameters on resonance of speech in cleft lip and palate patients. An interdisciplinary study. J Orofac Orthop 62(3): 202-223.

12. You M, Li X, Wang H, Zhang J, Wu H, Liu Y et al, (2008) Morphological variety of the soft palate in normal individuals: a digital cephalometric study. Dentomaxillofac Radiol 37(6): 344-349.

13. Abu Allhaija ES, Al-Khateeb SN (2005) Uvulo-glosso-pharyngeal dimensions in different anteroposterior skeletal patterns. Angle Orthod 75(6): 1012-1018.

14. Soheilifar S, Soheilifar S, Soheilifar S (2014) Upper Airway Dimensions in Patients With Class II and Class I Skeletal Pattern. Avicenna J Dent Res 6(2): e23300.

15. Akcam MO, Toygar TU, Wada T (2002) Longitudinal investigation of soft palate and nasopharyngeal airway relations in different rotation types. Angle Orthod 72(6): 521-526.

16. Kandasamy S, Goonewardene M (2014) Class II malocclusion and sleep-disordered breathing. Semin Orthod 20(4): 316-323.

17. Igawa H, Nishizawa N, Sughihara T, Inuyama Y (1998) A fiberscopic analysis of velopharyngeal movement before and after primary palatoplasty in cleft palate infants. Plast Reconstr Surg 102(3): 668674.

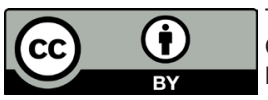

This work is licensed under Creative Commons Attribution 4.0 Licens DOI: 10.19080/ADOH.2018.08.555726
18. Akguner M (1999) Velopharyngeal anthropometric analysis with MRI in normal subjects. Ann Plast Surg 43(2): 142-147.

19. Jakhi SA, Karjodkar FR (1990) Use of cephalometry in diagnosing resonance disorders. Am J Orthod Dentofacial Orthop 98(4): 323-332.

20. Jhonston CD, Richardson A (1999) Cephalometric changes in the adult pharyngeal morphology. Eur J Orthod 21(4): 357-362.

21. Verma P, Verma KG, Kumaraswam KL, Basavaraju S, Sachdeva SK, Juneja S (2014) Correlation of morphological variants of soft palate and need's ratio in normal individuals: a digital cephalometric study. Imaging Sci Dent 44(3): 193-198.

22. Guttal KS, Breh R, Bhat R, Burde KN, Naikmasur VG (2012) Diverse morphologies of soft palate in normal individuals: a cephalometric perspective. J Indian Acad Oral Med Radio 24(1): 15-19.

23. Jeans, WD, Fernando DC, Maw AR, Leighton BC (1981) A longitudinal study of the growth of the nasopharynx and its contents in normal children. Br J Radiol 54(638): 117-121.

24. Haapanen ML, Kalland M, Heliovaara A, Hukki J, Ranta R (1997) Velopharyngeal function in cleft patients undergoing maxillary advancement. Folia Phoniatr Logop 49(1): 42-47.

25. Pepin JL, Veale D, Ferretti GR, Mayer P, Levy PA (1999) Obstructive sleep apnea syndrome: hooked appearance of the soft palate in awake patients-cephalometric and CT findings. Radiology 210(1): 163-170.

26. Lowe AA, Santamaria ID, Fleetham JA, Price C (1986) Facial morphology and obstructive sleep apnea. Am J Orthod Dentofac Orthop 90(6): 484491.

27. Praveen BN, Amrutesh S, Pal S, Shubhasini AR, Vaseemuddin S (2011) Various shapes of soft palate: a lateral cephalometric study. World J Dent 2(3): 207-210.

\section{Your next submission with Juniper Publishers will reach you the below assets}

- Quality Editorial service

- Swift Peer Review

- Reprints availability

- E-prints Service

- Manuscript Podcast for convenient understanding

- Global attainment for your research

- Manuscript accessibility in different formats

( Pdf, E-pub, Full Text, Audio)

- Unceasing customer service

Track the below URL for one-step submission

https://juniperpublishers.com/online-submission.php 